Pediat. Res. 3; 459-463 (1969)

\title{
The Swing of the Pendulum
}

\author{
Presidential Address to the American Pediatric Society ${ }^{[6]}$
}

Louis K. Diamond ${ }^{[7]}$

Department of Pediatrics, University of California School of Medicine, San Francisco, California, USA

Members and Guests of the American Pediatric Society:

May I voice, first, my deep appreciation of having been elected President of the Society and thank the membership for this high honor.

I have chosen as the title of my talk 'The Swing of the Pendulum'. I believe this is descriptive of the turn of events in the progress of pediatrics and, hopefully, it may also be predictive of coming changes.

It is quite customary for the presidential address either to review the scientific work of the incumbent, often an easy task, since it is well known to him, or to delve into the history of the Society, commenting on its leaders and their opinions, or to review present trends and practices. The first alternative-to talk about one's 'life's work' - sounds rather terminal. To make an interesting story of it, the teller should have a good memory, and hope that other people have not. For all these reasons, $I$ avoided this direction. Instead I have combined the other two alternatives so that this talk is chiefly on the future of pediatrics, but in part it is a review that required my looking back through the published Transactions of the Society, an interesting experience in itself. We are now entering the 81st year of the Society's existence, including two war years without annual meetings. We have had many distinguished members, and especially eminent physicians as presidents. In addition to the great names in pediatrics such as JACOBI, ROTCH, HOLT, HowLAND, Abt, Blackfan, Park, Gamble, and Powers, to name a few, how many of you know that WrLliam OsLer was president in 1892, and DAVID EDSALI (later Harvard's Dean) in 1910? Your speaker more firmly grips the gavel, said to have been made from a tree in OsLER's garden, in hopes of deriving strength and confidence from it.

The subjects, not only of their addresses but of the papers given at the meetings, throw interesting light on pediatrics and pediatricians at succeeding times. More important, they show some trends, some mistaken concepts, and some prophetic, and at that time incredible, ideas. Something can and should be learned from history but, unfortunately, seldom is.

Pediatricians, from the earliest appearance of the specialty, were concerned primarily with the growth and development of infants and, therefore, with infant feeding. When circumstances prevented or prematurely stopped breast-feeding, artificial feeding, in lieu of the relatively rare possibility of hiring a wet-nurse, was an oft unsuccessful and dangerous alternative for the young infant. Cow's milk was recognized as the best substitute, but it was too 'rich' in protein (then called 'proteids') and in salts; it was often unclean, easily spoiled through lack of adequate refrigeration and poor handling and, most disturbingly, contaminated with bacteria before or after delivery. Digestive disorders, intestinal infections, and malnutrition in infants, especially those not completely breast-fed, were almost the rule. It is difficult to imagine today the dozens of problems faced then in trying to make artificially fed infants thrive.

Recognizing that breast-feeding had, among other well-known merits, a varying composition best suited to the needs of the growing infant, physicians and nutritionists analyzed human milk and attempted to modify cows' milk accordingly for the infant's requirements. Too often the infant acted distressed or became ill, but this was blamed on improper modification of the milk rather than the now more likely spoilage and bacterial contamination and alteration. Rigidity and meticulous formulation of artificial feedings therefore became established practice. At the turn of the century and well into the 1900 's, percentage feeding, as developed by Thomas Morgan Rotar in Boston, was considered the most scientific and pediatrically approved way of raising non-breast-fed infants. This consisted of producing a formula that contained basically, like human 
milk, fat $4 \%$, sugar $7 \%$, protein $1.5 \%$, and salts $0.2 \%$ in $100 \mathrm{ml}$ of fluid [2]. Variations were made according to the age of the infant and its response, judging by appetite, comfort ('colic', or crying with squirming, which was considered to mean 'colic'), weight gain, and particularly the character of the stools, always minutely examined for color and content of curds, fat globules, consistency and odor. Milk laboratories such as the famous Walker-Gordon Laboratories were available in Boston, New York, and some of the other large cities. To such laboratories, the pediatrician could send a prescription for a formula to be prepared and delivered daily to the home of the infant. It was admitted that to 'modify' milk at home required intelligence and considerable care. It was necessary to have at hand $12 \%$ cream or $8 \%$ cream, plain milk, sugar (lactose) solutions varying from $5 \%$ to $10 \%$, boiling water and limewater. In preparing the formula, for example, for a 1- to 3-month-old infant, the parent or, better, an experienced nurse assembled $4 \frac{1}{2}$ oz. cream, $4 \frac{1}{2} \mathrm{oz}$. milk, $2 \mathrm{oz}$. of $7 \%$ sugar, $25 \mathrm{oz}$. water, and $1 \frac{1}{2} \mathrm{oz}$. limewater. After orderly mixing and sterilizing in individual bottles, the infant was given each feeding at regular intervals. Variations in ingredients were made with the age and size of the child and especially with the examination of the stools. From the first week through the 18th month, ten modifications of cow's milk were prescribed; thereafter whole milk was permitted.

The addition of other foods was usually deferred until the 8th or 9th month and then only cereal gruel could be added in place of the sugar in the formula. By the 10 th or 11 th month, home-squeezed beef juice might be begun. In the second year, well-cooked cereals, beef juice and, after most of the teeth were in, scraped beef, stale or oven-dried bread, strained fruit (orange juice only as early as the 15th month) and later egg (every other day) were gradually introduced.

Incidentally, the limited quantities of formula at each feeding (maximum $4 \frac{1}{2} \mathrm{oz}$. at the third month, $51 / 2 \mathrm{oz}$. at the fifth month, $7 \mathrm{oz}$. at the ninth month, etc.) were in part dictated by the supposed capacities of the stomach, as measured in infants of various ages at post mortem examinations when this organ was often an inelastic sack.

Obviously, feedings, especially during the first year, were low in proteins, also in minerals, and especially in vitamins. Many babies grew up small by present standards, but they must have been tough. And they were well disciplined. The prestigious pediatrician of those days gave new parents a set of rules in the same authoritative manner as did Moses when he came down from Sinai. And the language was probably not much different. Indeed, it sounded like 'thou shalt not' pick up the baby except at feeding times. In between, leave him in bed and close the door if he cries. Do not feed soft solids before 1 year, and add these slowly so that a varied diet is not reached before 18 months or more. If, as psychiatrists claim, disturbed adults can be made to dredge up memories of infantile deprivations and emotional traumas, what an earful the analysts must have gotten from the generation raised between 1900 and 1920 . There probably were recalls of unappeased hunger and thirst, long dark solitary nights, wet soiled bottoms, even hands pinned down to prevent the solace of thumb-sucking.

In the late 1920 's, cracks in this rigid infant-feeding and -raising program began to appear. Simpler whole milk with dextri-maltose or evaporated milk with Karo formulae came into use. A little t.l.c. was even permitted openly. And a pediatrician named Dr. Crara DAvIs [1] claimed to prove that if a 6-to 9-month-old infant were offered a tray in his high-chair and fed what his hand happened to hit every time he slapped it down, he developed a vigorous appetite and over a period of a week would have ingested a balanced diet, even though he might have filled up on 6 eggs at one meal. Anyway, the wall was breached. Over the next 25 years, it became apparent that babies could thrive on almost any reasonable food. And parents were told it was better not to thwart them lest they develop inhibitions. Discipline became a forbidden word and act. And everything was freely given children by adults except a set of rules to. live by.

If there was an occasional dissenting voice, there was also a popular pediatric book to quote in support of 'laissez-faire'. How much of the present 'hippie' attitude stems from such a background of permissiveness is a matter of opinion. But this mode of behavior is beginning and is eventually bound to change, not necessarily by external reaction against it. More likely the problem is generating its own solution. Many of this generation's young parents, not accustomed to being denied their freedom or of giving in to the request of others in or outside their own households, will not tolerate inconsiderate demands and free action in others, even be they their own children. Discipline may thus creep back in. Maybe the pendulum has reached its zenith and is beginning to swing back. One can only hope it won't go too far to the right again and that infants and children may yet achieve the ideal state of comfort, contentment, and carefree happiness combined with security.

Dipping further into the history of this Society and noting particularly the papers that were presented at the meetings, the turn of the century saw an increasing interest in infectious diseases with particular emphasis on symptoms and signs by which the condition should be recognized. But gradually, bacteriologic and other laboratory support for clinical diagnoses were being 
sought and special tests were reported in greater length at succeeding meetings. Here again, the pendulum may have swung too far. Laboratory medicine has replaced bedside diagnosis, and routine procedures, to be ordered before a 3:00 p.m. deadline set by the technicians for accepting specimens for analysis, have taken the place of thous lit ul consideration of the patient's symptoms and signs. A comparison of two case reports given 55 years apart illustrates this. The first is from a presentation before a learned pediatric society in 1912 . The description was as follows:

A 16-month-old male infant was admitted with swelling of first the left foot, then the right, quickly followed by a spreading red rash on the buttocks and by edema of the testes. Crying from colic was intermittent but severe. The glands were not enlarged. The throat showed no membrane nor inflammation. There were some bruises in the skin on the extremities. The abdomen, on percussion, showed enlargement of liver dullness from the 5 th interspace to 2 fingerbreadths below the costal margin. The next day, although there was no fever, both eyes became swollen and there was increased swelling of the ankles and feet. Colic seemed irregularly present and a dark-reddish, foul-smelling stool was passed. The abdomen was resistant to palpation but no masses could be felt. On the 3 rd day there was slight fever, the puffiness of the eyes and swellings of the feet were less, but a red rash appeared on each cheek. At the same time, the lower back, the buttocks, and the thighs revealed red papules, some of which became hemorrhagic. On the 4th day the feet were swollen again and the hands became puffy. In the ensuing two days the rash on the face and the lower extremities extended and the old areas became dark with blood, but the abdomen was softer and the child appeared more comfortable. The hemoglobin measured $70 \%$. By the 10 th day improvement was more marked and the infant was sent home.

Note the careful description of what was detectable through the use of the senses alone. The diagnosis today would probably be allergic or Schoenlein-Henoch's purpura. Then it was called systemic manifestations of a cutaneous disease. Contrast this with a case history presented recently of a 2-year-old child admitted to the hospital with the following story:

Swelling of the joints occurred 2 days previously. There was pain in the abdomen and vomiting on 3 occasions. A rash appeared on the hands and feet. Examination was otherwise negative. T.P.R. normal. Diagnosis: Allergic purpura most likely, but to be considered and ruled out: 1 . rheumatic fever, 2. rheumatoid arthritis, 3. septicemia, 4. mononucleosis and 5. leukemia. Laboratory tests were ordered, as follows: Blood cultures $\times 3$; GBC, Sed rate; ASL titer; febrile agglutinins and heterophile antibody tests; serum albu- min and gamma globulin levels; BUN; liver function tests; Addis count; $x$-ray of chest, abdomen and extremities; and before discharge, skin tests for allergy.

In the first case, the lack of available laboratory measurements that might assist in diagnosis confined the physician to a careful recording of what could be seen, heard, or felt. In the second case, although the same findings were probably present, the emphasis obviously was on laboratory confirmation or exclusion of many diagnostic possibilities, some of which seemed rather far-fetched. The attitude has become prevalent that laboratory data are more reliable in making a diagnosis than the use of the senses and since, through micromethods, a few samples can be analyzed for innumerable factors, why delay in obtaining all possible measurements. The fallacy in this is quite obvious. Reliance on laboratory measurement to this extent soon tends to supplant thinking. Eventually, and maybe even today in the larger laboratories, a printed slip of paper may offer the results of all the tests within a short time and even suggest the diagnosis. It may be, as claimed, less troublesome to the patient to be bled only once, but if nothing else, the cost is not inconsiderable. How can this trend toward reliance on laboratory data alone be redirected? I believe it is the responsibility of senior physicians to comment on it and to criticize it severely. If, repeatedly, it is declared unacceptable and censurable, possibly it will become a less-common practice.

A final and most important swing of the pendulum is that which took place in pediatrics or possibly in all of medicine about a generation ago. Before the advent of antibiotics, corticosteroids, and the innumerable new therapeutic agents, much of the basic research in medical science was in the hands of the 'pure scientists' -the Ph.D.s, many of whom had relatively little interest in the practical clinical application of their laboratory knowledge, often derived from animal or avian experimentation. Occasionally, the overt attitude was that the Ph.D. medical scientist, restricted in his activities to his ivory tower, would be slightly debased if he applied his findings to human medical problems; in essence, he had no common meeting ground with the clinician, who in turn had little interest in 'pure' laboratory research.

With the start of World War II, so many scientists-both Ph.D.s and M.D.s-were drawn into needed medical research, both basic and practical, and found it not only tolerable but often exciting, that this schism rapidly healed. Cooperation in the war effort was the order of the day. Not infrequently, one did not know whether one's neighbor at a meeting or in the laboratory was an M.D. or a Ph.D., and the mixture proved stimulating and productive. The introduction of antibiotics required the support, knowledge, and 
experience of the biochemist, the physical chemist, and the bacteriologist. Once the pattern had been established it was readily accepted. More important, the 'pure' scientists began to attract the bright young men in and from medical schools. More and more basic research was carried on by M.D.s with clinical experience and patient interest. In pediatrics, there were added reasons, as will be mentioned later, for undertaking basic research. In addition, the rapid increase in monetary support obtainable through the OSRD, the NIH, and the NRC, as well as the Armed Services, made research doubly attractive.

Turning now to pediatric research, the founders of this Society were general practitioners or internists who developed a special interest in children. When, after a number of years, they limited their practice to the young, they were recognized as pediatric specialists. Developing their knowledge on the one hand, of adolescents (lately named ephebeology) and on the other, of young infants, soon extended the pediatrician's scope beyond puberty as well as back into early infancy. Initially, because of the high infant mortality, especially in the non-breast-fed baby, the pediatrician concentrated on infant and child feeding and growth and development from the first few weeks of life until puberty. Not infrequently, during birth and in the first days thereafter, serious damage occurred, often irreparable despite subsequent good care. Perforce, the pediatrician had to learn and become expert in the management of the neonate. The special anatomic, physiologic, and biochemical alterations occurring so dramatically and rapidly in the newborn during the transition from intra- to extrauterine life demanded special study, the development of new skills, and the full-time attention of still another expert. Neonatology became a logical extension of the specialty of pediatrics. But the fetus, even before he is subjected to the hazards of delivery-that dangerous period which Dr. CuEMENT SMrTH [5] has so aptly called 'the passage through the valley of the shadow of birth'-may be seriously affected by environmental factors altering his usually well-protected intrauterine existence. Two further logical steps in the accumulation of knowledge about the newborn required the study of the fetus and of the embryo. The fetologist certainly fills an important place in pediatrics. His understanding of the necessary adjustments of the prematurely born infants and his ability in managing them may decidedly improve the hitherto discouragingly low survival rate of the "premie'. His skill in handling an often amorphous-looking human-to-be excites wonder and admiration. Like the Army Engineers, the fetologists can adopt as their motto: 'The difficult we do today, the impossible tomorrow', and it must be tomorrow for by the following day the premature baby may be gone.
Embryology is a time-honored preclinical field of study. The embryologist faithfully pictured the gradual changes in structure of the developing organism, step by step. But he could not follow the course of his subject to its logical end, the birth of the fully formed individual. After the baby was delivered, he was left with only a memory and an empty uterus. Little wonder the 'pure' embryologists have virtually disappeared. In their place, there is now the pediatrician who is anxious to know what made the newborn look like that and pursues his development back through fetal stages into embryonic life, even to his beginnings as an impregnated ovum. One minute earlier will find the embryologist talking to the geneticist.

The logic of such expanding subspecialization for the pediatrician is self-evident. Although it is necessary for the biochemist, the enzymologist, the geneticist, or the molecular biologist to concentrate in his field of special study, it would be unfortunate if a chasm once more developed between the preclinical and the clinical sciences, between laboratory-oriented and clinically-oriented medicine including, especially, the new area of community-oriented pediatrics, lest the latter be allowed to convert to a social science rather than a medical science. An essential phase of the research or the laboratory development of the medical scientist should remain basic training in a clinical field related to his special interest. In this respect, pediatrics offers the best background for genetics, developmental biology, and related disciplines, for it stimulates and keeps open lines of communication between the research worker and the clinical scientist. OsLer [3], in his presidential address in 1892, said: 'A radical error is the failure to recognize that the results of specialized observation are at best only partial truths which require to be correlated with facts obtained by a wider study'. We are poised at the beginning of a new era of promise when an interplay among various disciplines will bring great benefit to child health in our society. The almost unimaginable storehouse of knowledge that has accumulated in biochemistry, genetics, and immunology cannot remain only a pure intellectual pursuit but must be brought to bear on the practical problems that confront us every day in steering our children to a mature and healthy adulthood. Hopefully, such adults will be better able to handle the complex problems of the world of today and of tomorrow.

The coming of age of medicine when expert care will consist not just in the repair of injury and cure of disease but in their avoidance and prevention may well be ushered in by the golden age of pediatrics - a specialty which must soon assume responsibility for more than half the population on this earth. Yet, for the pediatrician to be responsible for the care of the child-and this has lately been publicized as 'total 
care', truly a redundant and 'Madison Avenue'-ish term, for when did a good physician accept or give anything less than total care?-obviously requires the close cooperation of several subspecialists in pediatrics. By building better infants and children into better adults, the traumas that make humans act less human, or more human, depending on one's point of view, may be avoided. Pediatrics or, to use a broader term, developmental human biology with its great potential of offering a satisfying career and work area in all the subspecialites, should increasingly attract the bright and inquisitive minds. At the same time, a devotion to the betterment of the individual child will eventually benefit the whole race. As you review the many interesting and stimulating papers offered at these meetings, you must agree that this evaluation of our present status is not exaggerated and my hopes for our future are not unduly optimistic.

In conclusion, I am reminded that more than a generation ago, JoHN RURAH [4], president of this Society in 1925, prophesied:

'A hundred years will soon go by,

Our places will be filled

By others who will theorize

And talk as long and look as wise,

Until they too are stilled.

And I predict no one will know

What makes a baby gain and grow.'

My prediction is quite the reverse. In far less than half that time, the pediatrician will know exactly what makes a baby gain and grow. But it won't be a oneman job, nor the responsibility of one subspecialty. Pediatrics may then be regarded as a benevolent hydra, its nine heads being each of the disciplines previously mentioned. Or possibly a better analogy is a tree, with many roots each representing a subspecialty. All of these-in one way or another-will be the province of that all-around investigator, scientist and physician, the pediatrician of the future.

\section{References and Notes}

1. Davis, C. M.: The self-selection of diet experiment. Ohio State med.J. 34: 862-868 (1938).

2. Holt, L.E.: Diseases of infancy and childhood, Chapt. 1-4, Sect. II (Appleton, New York 1897).

3. Osler, W.: Remarks on specialism. Trans. Amer. Pediat. Soc. 4: 6-13 (1892).

4. Rurah, J.: Quoted by Goldbloom, Alton: The evolution of the concepts of infant feeding. Arch. Dis. Childh. 29: 385-390 (1954).

5. Sмrтн, G.A.: The valley of the shadow of birth, Amer. J. Dis. Ghild. 82: 171-201 (1951).

6. Delivered at the time of the Annual Meeting of the Society, April 30, 1969.

7. Requests for reprints should be addressed to Lours K.Diamond, M.D., Professor of Pediatrics, University of California, San Francisco Medical Genter, San Francisco, Galifornia 94122 (USA). 